\title{
Retraction Note: Study on the structure and magnetic properties of Gd-doped LTPMnBi
}

\author{
Jinhui Huang • Wei He • Tonghan Yang • Guorui \\ Xiao • Guoren Huang • Xiaowei Wu • Peiqi Chen
}

Published online: 12 August 2021

(C) Springer Nature B.V. 2021

Retraction Note to: J Nanopart Res (2020) 22:180. https://doi.org/10.1007/s11051-020-04901-y

The Editor-in-Chief and the Publisher have retracted this article. The article was accepted as part of a guest-edited special issue in Journal of Nanoparticle Research. Before the special issue was finalized, the Editor-in-Chief detected problems with editorial handling and peer review and decided not to proceed with the special issue [1].

Post publication peer review found that this article is out of scope for the journal, which focuses on original contributions on nanoscale phenomena and processes, and does not meet the standards required by the journal.

The online version of the original article can be found at https://doi.org/10.1007/s11051-020-04901-y

J. Huang $\cdot$ W. He $(\bowtie) \cdot$ T. Yang $\cdot$ G. Xiao $\cdot$ G. Huang $\cdot$

$\mathrm{X} . \mathrm{Wu} \cdot \mathrm{P}$. Chen

Key Laboratory of New Processing Technology for Nonferrous Metal and Materials (Ministry of Education), School of Resources, Environment and Materials, and College of Chemistry \& Chemical Engineering, Guangxi University, Nanning, China

e-mail: wei_he@gxu.edu.cn

J. Huang

e-mail: H-Cherish@foxmail.com

T. Yang

e-mail: yangthan199@163.com

G. Xiao
The corresponding author stated on behalf of all coauthors that they agree to this retraction.

\section{References}

1. Pinna, N., Clavel, G. \& Roco, M.C. The Journal of Nanoparticle Research victim of an organized rogue editor network!. J Nanopart Res 22, 376 (2020). https://doi. org/10.1007/s11051-020-05094-0.

Publisher's note Springer Nature remains neutral with regard to jurisdictional claims in published maps and institutional affiliations. e-mail: xgr_tyut@163.com

G. Huang

e-mail: 15951701683@163.com

$\mathrm{X} . \mathrm{Wu}$

e-mail: 904189166@qq.com

P. Chen

e-mail: nancy3022@163.com

W. He $\cdot$ T. Yang

Guangxi Key Laboratory of Processing for Non-ferrous Metallic and Featured Materials, Guangxi University, Nanning, China 